\section{Muitas vozes: algumas notas}

\author{
Muitas vozes \\ Ferreira Gullar \\ [José Olympio, 1999, 118 p.]
}

\section{Alcides Villaça}

1.

Não é difícil distinguir e descrever procedimentos da forma poética, que quase sempre se oferecem à primeira vista; nem é muito difícil categorizá-los e ordená-los nessa mesma ordem da construção ostensiva. Sabemos, no entanto, que nosso sentimento da poesia não se deixa espeIhar nos reconhecimentos descritivos: imantado pelo poético, adere à natureza deste e resiste à exteriorização mais fácil, numa experiência silenciosa que é ao mesmo tempo recompensa e inquietação. A crítica nasce desta inquietação, porque quer qualificar, segundo seus critérios, aquela precisa recompensa.

Vista de forma panorâmica, a melhor poesia de Ferreira Gullar pode ser reconhecida, desde A luta corporal, num quadro de procedimentos gerais, muito marcados e mesmo obsessivos: o poeta sempre se interessou em surpreender o múltiplo, o simultâneo, o diverso e o movimento sob as aparências implacáveis do uniforme, do linear, do compacto e do estático; ele sempre buscou traduzir a experiência vertiginosa e aprofundada que, dentro do sujeito, corre num tempo outro, reagindo à seqüência mecanizada dos acontecimentos. Nas diferenças de qualidade desses tempos - nas diferentes velocidades do tempo - está uma poderosa fonte poética de Gullar: há a ação do passado sobre o presente, há o seu ser e o do outro, há a presença do lá dentro do cá, há o variado pulsar da vida - e as sombras recorrentes da morte. O desafio aceito pela arte surge para o 
poeta como tradução de um tempo no outro. Questão essencial: deter do instante que passa ou que já passou a intensidade que costuma se perder nos modos da vida apressada e desatenta; com a percepção empenhada, surpreender, em meio à prosa impura da vida, a insuspeitada matéria poética que de repente salta dela.

Diante do absoluto obscuro que é a morte, a diversidade dos tempos é a garantia do que é vivo, a intensidade de cada coisa é a evidência viva da melhor percepção. "Minha poesia" disse Gullar em palestra recente, "é inteiramente dependente da prosa" Entenda-se: da prosa vital que corre no tempo comum e que carrega, em bruto, a surpresa do poético.

Habituado a esses reconhecimentos gerais, ou mesmo familiarizado com alguns reiterados recursos de estilo, nem por isso o leitor de Gullar deixa de sentir em cada poema um novo poder de singularização. É que o leque necessariamente finito dos procedimentos alimenta-se, nesta poesia, da vida mesma, tão farta em aspectos, tão intensa em cada um

2.

O título do novo livro de Gullar - Muitas vozes - já soa em si mesmo como um compasso súbito retomado de uma fala familiar, que esteve por longos anos interrompida Estamos de novo diante da matéria múltipla e do sujeito provocado que a recolhe, sujeito sempre sensorial, impressivo e reflexivo - creio que nesta ordem. De certo modo, Muitas vozes continua Barulhos, que continuava Na vertigem do dia, que acolhia ecos e rebentações do Poema sujo, cujo modo de composição se prenunciava no belíssimo "Uma fotografia aérea" que, já em Dentro da noite veloz, orquestrava tão belamente simultaneidades de espaços e de tempos. No entanto..

No entanto este novo livro traz consigo as marcas de um tempo que já excedem a força inaugural das representações simbólicas mais ansiosas: gravam-se no corpo e no espírito com a dura confiança da primeira velhice, que lhes dá uma nova tonalidade, sem contudo desmentir o movimento orgânico de um caminho tão pessoal

Talvez nunca tenham sido tão fortes as homenagens de Gullar à vida, no que ela tem de multiplicativo, porque complexa, e de belo, porque intensa. Não me refiro exatamente à força da qualidade estética, já assegurada desde o livro de estréia; refiro-me à força vivencial que escapa da melancolia e da nostalgia, tão previsíveis e justificáveis no outono alto, e que agora rende comovido tributo tanto ao acúmulo das experiências já vividas como ao sempre intenso desejo das novas:

Tive um sonho conclusivo

sonhei que a vida era um sonho 
e quando a vida acabava

o sonhador acordava

vivo

|"A August Willemsen"|

Tanto mais brilha a vida quanto mais se espelha contra o morrer. Assim também pode ocorrer com as palavras: aprendem a depurar-se mais e mais quanto mais entendem do silêncio a que se estão furtando. Este poeta, a entrar nos setenta anos, está especialmente incisivo nos poemas em que a resposta dos sentidos é ainda mais forte que o império das lembranças. Se "o silêncio era frio/ no chão de ladrilhos/ e branco de cal/ nas paredes altas" "lá fora/ o sol escaldava" O frio de dentro e o calor de fora unem-se pela qualidade da luz: "branco" e "sol" ("Evocação de silêncios") A luz voraz que consome "nossos mortos/ acima da cidade" está também "zunindo feito dínamo/ naquelas manhãs velozes" ("Manhã").

Silêncio e brancura não são, para Gullar, as instâncias abstratas da chamada poesia pura: são qualidades sensoriais da vida. Não parece atraí-lo o álibi ingênuo do "branco da página" nem a rarefação das palavras cuja perfeição se inscreve na ordem da celebração estética autocontemplada. Num dos poemas inesquecíveis do livro, "Fotografia de Mallarmé" os versos introdutórios

$$
\text { é uma foto }
$$

premeditada

como um crime

estão falando apenas da fotografia posada do poeta estatuário ou daquelas premeditações mallarmeanas que desviam a poesia dos impactos da vida, inscrevendo versos no cosmo altivo das palavras-mesmas - mundo da beleza petrificada? A poesia, como na foto de Mallarmé, estará melhor nesse tão estudado "arranjo" do "adrede preparado" da "manta equilibrada" da "caneta detida" - ou será preciso buscá-la (e encontrá-la) na expressão facial do poeta morto, em cujo olhar o olhar do poeta vivo surpreende aquele desejo que nenhum poema pode satisfazer? Homenagem esquiva, tão comovida quanto distanciada, o poema "Fotografia de Mallarmé" lembra a admiração dividida do Gullar pelo Ioão Cabral que, tão intenso na realização de tantos poemas vivos, doutrina em outros a poesia ao modo do cálculo e do conceito, armado e premeditado como quem se educa com as pedras (veja-se o poema "Nãocoisa" que, em Muitas vozes, pode armar um sugestivo diálogo com a poesia cabralina). Num rumo distinto, a poesia de Gullar quer escavar o que é também a insuficiência das palavras, um pouco aquém da força mesma da vida, da força dramática cuja expressão se alcança, sim, com os nomes, mas que não se deixa encerrar inteiramente neles:

mas eis que 


$$
\begin{aligned}
& \text { teu olhar } \\
& \text { Encartra o dele } \\
& \text { } \because \Xi \text { iarmél que } \\
& \text { ¡li } \\
& \text { งิ fundo } \\
& \text { da mere }
\end{aligned}
$$

3.

Por amor à vija e ac canto de vitalidade abscluta que. por isso mesmo, nunca se realiza plenamente Gullar rela- - viza o aizance do poema e o do próprio corpo. Poema e corpo aliás quase se coniundem. quando a narureza das ca.àuas é entendida e tomada como abrigo possive. de uma expanș̃a corporal Com a prática dessa relativização

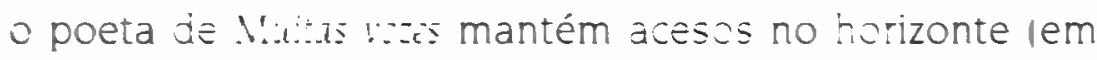
̇.argamento que sublima e adia a morê, ss critérios de um deseic sempre insatisteito porque insatisiatéria é toda experiência em sua sirgular beleza. tomada como indício e zromessa do belo absoluto aralizado pela marte

$\therefore$ luz e o calor ias pesscas e dos acontecimentos surgem para Gü. ar num grau de excesso e de transbordamen-

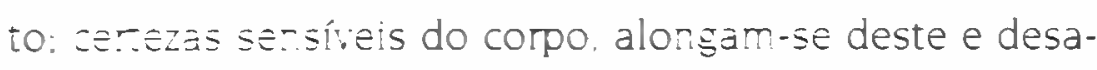

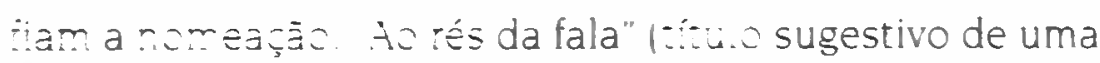

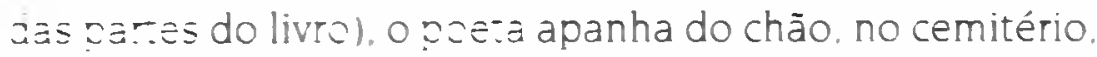
um rape amarrotado onde grava em palavras o amor pelo :Hino zue partic: o poema é só a notícia ciessas palavras e daquela flor deixada no dia de finados score o mármore do túmulo mas a pcesia salta do gesto e convoca um sentido máximo de paixão

O absurdo da existência não se dá como tema filiosófico para o poeta maranhense que. desde menino extraiu iķ̧ڤ̄es naturais da luminosidade de sua Sà̃ Luís lliçèes tão icres que o acompanharam no longo exílio I: o absurdo é o belo mesmo. nas tantas epifanias que duram tão pouco e tanto prometem, esiimulando a cada vez nossa fome deias Absurdo é Ḿ́crer no Rio de laneiro' em meio "à festa da vida" "como parte que és dessa orquestra regida pelo sol

O impacto caprichoso le por vezes dramáticol da beleza é reconhecido em pleno cotidiano: materializa-se num Electra II que, "quase ao alcance das màns" surge rasaric na rua Paula Matos. O prosaico aviāo da ponte aérea, que não perturba a expectativa de ninguém. perturba o poeta e detona um poema. nà̃ porque seja um aviàc mas porque trouxe consigo a beleza do imprevisto - tal como uma imagem poética. Com as olhos possuidos do espanto de um homem primitivo um aviāo é visto com a surpresa da primeira vez:

Foi um susto vè-lo: vasto pássaro metálico

azul parado 
lum

segundol

entre

os ramos rente

aos velhos telhados

Um símile se produz na associação Electra II/ poema: o prosaico de um ruído entre outros, de uma visão entre outras, que integra sem dissonância o quadro urbano, é percebido pelo poeta no aspecto distintivo de uma brevíssima aparição ("um segundo") que, no entanto, permanecerá para sempre. Visão repentina e ruído súbito, ainda assim quem reparará no avião regular da ponte aérea se não conservar, entre as tantas visões e os tantos ruídos da cidade. a possibilidade de um espanto? Em meio aos barulhos, o estampido de um avião, como a detonação da poesia, "por alto demais/ não pode ser ouvido"

O crédito aos acontecimentos como fonte primária e material de poesia está também em "Q'el bixo s'esgueirando assume ô tempo" Chegando a um sanatório, com "uma horrível/ maleta/ cor-de-abóbora" e "com medo de/ morrer" o poeta se depara com canteiros de crista-de-galo que, num relance, Ihe "parecem/ de fato cristas/ de galo" impressão alucinatória. Semanas mais tarde, vendo "um galo/ no meio das/ cristas-de-/ galo" o poeta imagina que continuava em marcha a alucinação da analogia entre no- mes e coisas, fazendo confundir bichos e plantas, "mas aí/ o galo andou e saiu de entre as plantas". A reversão da metáfora está completa: a linguagem da poesia não é "desvio" ou "deslocamento" da verdade realista; é a plena recuperação do primitivo olhar, que se surpreendeu com as correspondências do mundo natural e as aproximou num primeiro batismo, para muito depois vir a se surpreender de novo, quando a metáfora outra vez se justifica - e se emancipa do "desvio" passeando viva entre os canteiros

4.

O aproveitamento das experiências vividas como fonte direta da poesia gullariana poderia, em princípio, sugerir uma operação análoga à da poesia de um Manuel Bandeira - mas é preciso atentar para uma diferença profunda. que se esclarece nessa comparação e ajuda a singularizar o modo poético de Gullar. Para este, o detalhe sensível e material é quase que sistematicamente transposto para uma ordem maior explicitada, para um plano ostensivamente alargado, no qual o detalhe se inscreve em sua pequenez justamente para melhor se amplificar. Assim. os "rumores/ de cão/ e gato/ e passarinho' o poeta os ouve "deitado/ no quarto/ às dez da manhã/ de um novembro/ no Brasil" ("Ouvindo apenas"); assim, "uma nesga d'água vista na praia do lenipapeiro surge como "fragmento talvez/ da água primeira/ água brasileira" ("Evocação de silêncios"): assim, em "Pergunta e resposta" a mulher amada, 
que tem nome e sobrenome, é "poeta e musa do planeta Terra" referida ao sistema solar, à Via Láctea, aos "bilhões de galáxias/ que à velocidade de 300 mil km por segundo/ voam e explodem/ na noite" A identificação do que é mais determinado se faz no pressuposto de um tempo e de um espaço que se abismam; o reconhecimento do elemento sensível, mínimo em si mesmo, implica o reconhecimento das virtudes que não estão apenas nele, mas se irradiam para a órbita da infinitude. A dialética obsessiva da poesia gullariana encontra no centro da matéria mais imediata e recortada - precisamente aí - toda a potência da significação que se abre para o espírito:

Weissmann abre
escultor de hoje
a matéria
e mostra que dentro dela
não há noite mas
espaço
puro espaço
modalidade transparente
de existência
|“Poema para Franz Weissmann"|

A deliberada dependência da prosa, num poeta que de- tém a técnica de muitas formas de versos, é uma escolha tanto vital quanto política. Esta última já não tem, em Muitas vozes, a direção da denúncia e a plataforma dos conceitos; seu modo ativo está na construção atenta das relações do sujeito com os seres e os objetos do mundo. Manifestar a posse dessa condição inquieta de sujeito; expressá-la no âmbito de uma rotina capaz, no entanto, de negar-se enquanto tal, e súbito surpreender; empenhar o corpo e as palavras na multiplicação sensível tomada aos próprios fatos da vida - eis algumas das contribuições de Gullar para a nossa lírica, deste modo impulsionada para além do sentimentalismo mofino ou da estetização engenhosa. A disposição gráfica dos versos muito curtos e cortados não oculta o discurso prosaico, nem quer disfarçá-lo: torna-se, na verdade, critério de ênfase para a realização oral das palavras, de uma ênfase desconhecida nas tantas informações que se atropelam na vida moderna. O discurso espacialmente fragmentário dos poemas de Gullar é a sua forma de valorizar o tempo de cada palavra, de cada coisa, de cada sensação - tomadas em si mesmas, primeiro, e depois na rearticulação com a vida. Surpreender-se com um novo ritmo e novas ênfases na matéria da vida é uma forma justa de se ouvir o canto de Muitas vozes.

Alcides Villaça é professor de Literatura Brasileira da Universidade de São Paulo e poeta, autor de Viagem de trem [Duas Cidades, 1988], entre outros. 